\title{
Flora da Reserva Ducke, Amazonas, Brasil: Loganiaceae
}

D. Zappi ${ }^{1}$

Progel, A. 1868. Loganiaceae. In: C. A. F. Martius (ed.). Fl. bras. 6(1): 251-300.

Zappi, D. 1989. Flora da Serra do Cipó, Minas Gerais: Loganiaceae. Bol. Bot. Univ. São Paulo 11: 85-97.

Zappi, D. 1996. Loganiaceae. Flora fanerogâmica da Ilha do Cardoso 4: 9-13.

Zappi, D. 2005. Loganiaceae. In: M. G. L. Wanderley; G. J. Shepherd; T. S. Mehlem \& A. M. Giulietti (eds.). Flora fanerogâmica do estado de São Paulo 4: 261-271.

Árvores, arbustos, lianas ou ervas. Folhas opostas ou verticiladas, estipuladas (estípulas às vezes interpeciolares relembrando Rubiaceae), lâmina simples, margem inteira, às vezes muito reduzida. Inflorescências axilares ou terminais, em panículas cimosas ou cimeiras escorpióides, ou reduzidas e então fasciculadas ou flores solitárias. Flores monoclinas, 4-5(-8)meras, actinomorfas; cálice sinsépalo ou dialissépalo; corola gamopétala, tubulosa, prefloração valvar, imbricada ou contorta; androceu isostêmone, estames adnatos ao tubo da corola, alternos aos lobos; ovário súpero, bicarpelar e bilocular, cada lóculo com um a muitos óvulos de placentação axilar. Fruto cápsula septicida, septicidaloculicida ou baga.

Família extremamente heterogênea, com cerca de 25 gêneros de distribuição tropical e subtropical, raramente encontrada em regiões temperadas, possui 12 gêneros neotropicais, dos quais quatro são encontrados na Reserva Ducke, onde ocorrem 15 espécies.

\section{Chave para os gêneros de Loganiaceae na Reserva Ducke}

1. Ervas; inflorescências escorpióides

1. Arbustos, árvores ou trepadeiras lenhosas; inflorescências corimbosas ou cimosas, nunca escorpióides.

2. Arvoretas paquicaules; folhas cuneadas a espatuladas, mais de $30 \mathrm{~cm}$ compr.; pré-floração imbricada, flores 10-meras

2. Arbustos a árvores ou trepadeiras lenhosas, ramificadas; folhas lanceoladas a elípticas, nunca ultrapassando $20 \mathrm{~cm}$ compr.; pré-floração valvar, flores 4-6-meras.

3. Árvores ou arbustos eretos, desprovidos de gavinhas; folhas peninérveas; frutos capsulares, secos

1. Bonyunia

3. Trepadeiras lenhosas, com gavinhas; folhas 3-5-nérveas na base ou ligeiramente acima desta; bagas carnosas a lenhosas, indeiscentes

4. Strychnos

\section{Bonyunia}

Progel, A. 1868. Loganiaceae. In C.A.F. Martius (ed.). Fl. bras. 6(1): 251-300.

O gênero consiste de 4-5 espécies na Amazônia brasileira, Guianas e noroeste da América do Sul.

1.1 Bonyunia aquatica Ducke, Arquiv. Inst. Biol. Veg., Rio de Janeiro 1: 211. 1935. Fig. 1 g-i

Árvores até $15 \mathrm{~m}$ alt., casca levemente rosada, castanha internamente, alburno creme; ramos castanho-avermelhados, glabros, os mais velhos lenticelados. Pecíolos 4-5 mm compr. Lâmina foliar largamente elíptica a oboval, 3,56,5 × 1,8-3,5 cm, cartácea, glabra, basalmente cuneada a arredondada, apicalmente obtusa a truncada, nervuras secundárias (4-)5(-6) de cada lado da nervura central. Inflorescência dicasióide, terminal, pedunculada, flores em grupos de 3, com a flor central séssil. Flores 56-meras, até $2 \mathrm{~cm}$ compr.; cálice tubuloso, 3$4 \mathrm{~mm}$ compr., apicalmente denteado; corola 
valvar, roxa a alva, carnosa, serícea; tubo cilíndrico, lobos até $1 \mathrm{~cm}$ compr., lineares, fortemente revolutos na antese. Cápsulas biloculares, septicidas, ovóides, agudas no ápice, densamente tomentosas a glabrescentes quando maduras; numerosas sementes por lóculo, aladas, membranáceas.

Conhecida apenas no Amazonas.

Florestas inundáveis e beira de igarapés.

$\mathrm{Na}$ Reserva Ducke foi coletada apenas uma vez, com fruto.

11.VIII.1993 (fr) Ribeiro 1103 (INPA K NY).

Espécimes adicionais estudados: AMAZONAS: Rio Curicuriary [Uaupés], 21.XII.1931, (fl, fr) Ducke, A. s.n. (RB 23760; K isótipo); loc. cit., 17.XI.1936 (fl), Ducke, A. 354 (K).

Bonyunia aquatica difere de $B$. antoniaefolia Progel e de B. minor N.E. Br. devido às suas folhas completamente glabras, e de B. superba M.R. Schomb. devido à características do cálice, que em $B$. aquatica apresenta-se muito menor e com lobos denteados a agudos, ao passo que, em $B$. superba o cálice é maior e possui lobos expandidos. Embora existam coletas de $B$. minor nas proximidades de Manaus, na Campina da Ponta Negra (W. Rodrigues 8547, INPA), esta espécie parece estar restrita ao habitat de "campina" ou "campinarana", habitat este cuja representatividade na área da Reserva Ducke é muito pequena, não havendo registros da espécie para a área da flora.

\section{Potalia ${ }^{1}$}

Progel, A. 1868. Loganiaceae. In C.A.F. Martius (ed.). Fl. bras. 6(1): 251-300.

Gênero monotípico ocorrendo nas Guianas, Amazônia brasileira e Peru. Estreitamente relacionado com Anthocleista, de ocorrência Paleotropical.
2.1 Potalia amara Aubl., Hist. pl. Guiane 1: 394, tab. 151. 1775.

Arvoretas paquicaules atingindo $2 \mathrm{~m}$ alt., completamente glabras, ramos moles, ocos, não ramificados. Pecíolos até $2 \mathrm{~cm}$ compr. Lâmina foliar estreitamente cuneada a espatulada, 30-60 ×9-15 cm, membranácea, ligeiramente carnosa, base decurrente, aguda, ápice trusecon a apiculado, nervuras secundárias 14-20 de cada lado da nervura primária. Inflorescências dicasióides, terminais, curtamente pedunculadas, flores em grupos de 3, com a flor central séssil, com pares de brácteas triangulares em cada nó e subtendendo cada flor. Flores (não observadas, dados da literatura) 10-meras, curto pediceladas; cálice consistindo em dois pares de sépalas arredondadas de tamanhos diferentes, as mais internas mais longas, ca. $5 \mathrm{~mm}$ compr.; corola imbricada, carnosa, tubo cilíndrico, lobos patentes na antese. Fruto turbinado, mais largo e alvo na base, verde e mais estreito no ápice; numerosas sementes por lóculo, ovóides a aplanadas, cartilaginosas.

$\mathrm{Na}$ Reserva Ducke foi coletado apenas material em fruto.

4.VI.1993 (fr) Ribeiro 834 (INPA K NY); 18.I.1996

(fr) Pirani, J. R. 3653 (INPA); 3.I.1997 (fr), Sothers 977 (INPA).

\section{Spigelia}

Guimarães, E. F. \& Fontella-Pereira, J. 1969. Contribuição ao estudo do gênero Spigelia L. III. Loefgrenia 34: 1-18.

Gênero que compreende cerca de 40 espécies de distribuição neotropical, possui seu centro de diversidade nos campos rupestres do leste do Brasil.

${ }^{1}$ Este gênero é considerado atualmente como parte de Gentianaceae (ver Struwe, L. \& Albert, V. A. 2004. A monograph of neotropical Potalia Aublet (Gentianaceae: Potalieae). Syst. Bot. 29(3): 670-701. 2004. 


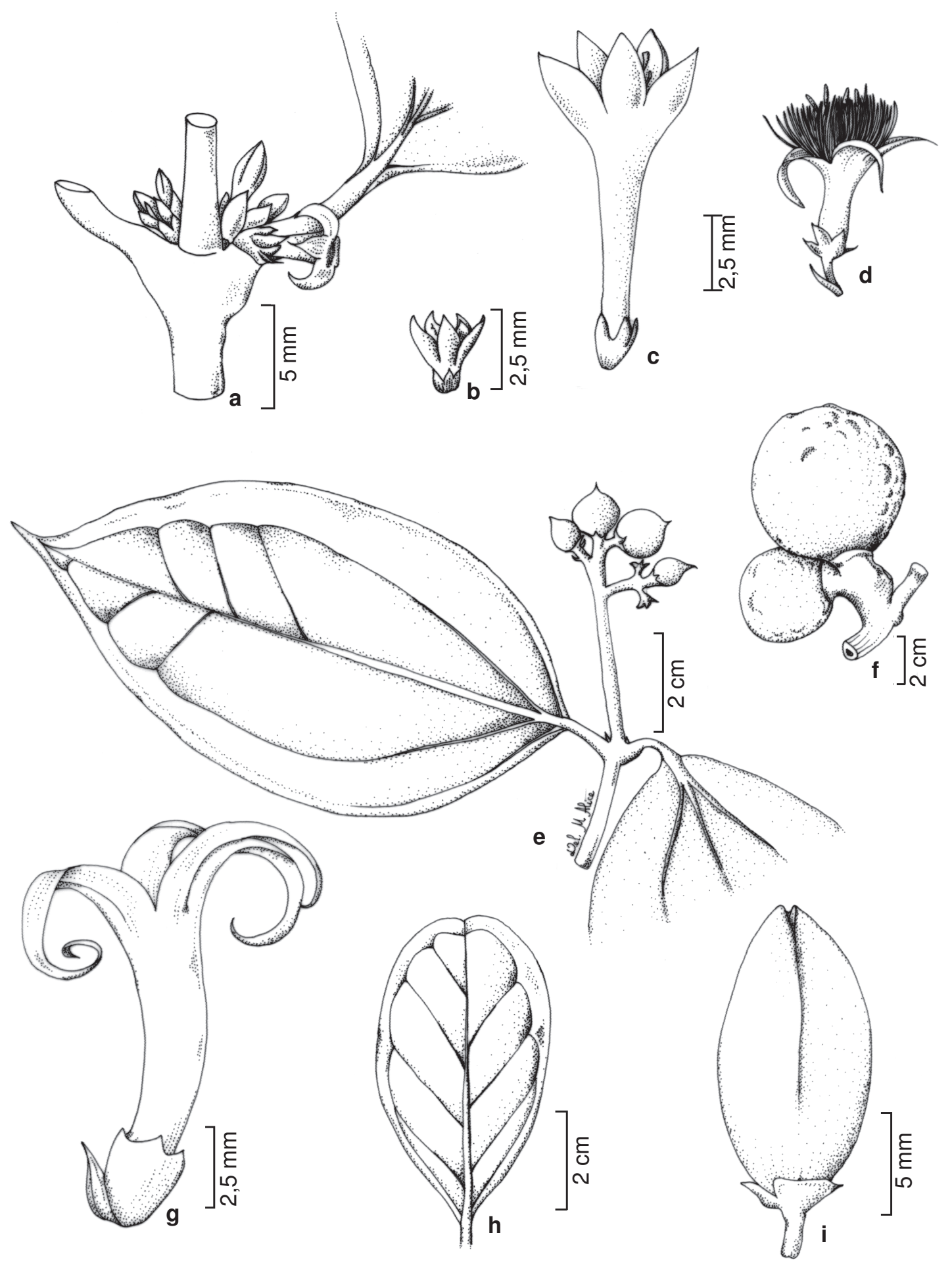

Figura 1 - a. Strychnos cogens, detalhe da inflorescência (L. Coelho s.n., INPA 5202); b. S. parviflora, flor com tubo curto (Spruce 2482); c. S. macrophylla, flor com tubo longo, (Ducke s.n., RB 22361); d. S. guianensis, flor com tubo intermediário (Acevedo Rdgz. et al. 8248); e. S. macrophylla, folhas e infrutescência (Coelho \& Mello s.n., INPA 3163); f. S. jobertiana, par de frutos (E. Ferreira 135); g-i, Bonyunia aquática, g. flor; h, folha; i. fruto (Ducke s.n., RB 23760). 
3.1 Spigelia anthelmia L., Speca. Pl. 1: 149. 1753.

Erva até $50 \mathrm{~cm}$ alt., completamente glabra. Folhas verticiladas (opostas na base), sésseis. Lâmina foliar rômbea a lanceolada, 4-10 cm compr., 1,5-4 cm larg., membranácea, levemente escabra nas margens, base cuneada a arredondada, ápice agudo, nervuras secundárias $4-5$ de cada lado da nervura primária, paralelas e fortemente ascendentes. Inflorescências escorpióides, apicais, geralmente mais do que uma por nó, alcançando $15 \mathrm{~cm}$ compr., desprovidas de pedúnculo ou pedúnculo indistinto. Flores 5meras, até 8-9 mm compr.; lobos do cálice ca. $3 \mathrm{~mm}$ compr., estreitos, agudos; corola valvar, alva a rosada, membranácea, tubo cilíndrico, lobos triangulares, sub-eretos. Cápsulas biloculares loculicidas, cada metade globosa, muricada no ápice; numerosas sementes por lóculo, alvoreticuladas, reniformes.

Amplamente distribuída no neotrópico, desde o nordeste do Brasil até o Caribe.

Áreas perturbadas, capoeiras; solo arenoso.

Sothers 989 (K), 1072 (K); Costa 484 (K); 5.V.1995 (fl) Vincentini 948 (INPA K NY)

Usada medicinalmente como vermífugo, esta espécie deve seu epíteto específico a esta propriedade.

\section{Strychnos}

Ducke, A. 1955. O gênero Strychnos no Brasil. Bol. Téc. Ins. Agr. Norte 30: 1-64.

Krukoff, B. A. \& Monachino, J. 1943. The American Species of Strychnos. Brittonia 4: 248-323.

\& Barneby, R. C. A. 1969. Supplementary notes on the American Species of Strychnos VIII. Mem. N.Y. Bot. Gard. 20(1): 1-93.

Trepadeiras, raramente arbustos eretos, dotados geralmente de gavinhas e/ ou espinhos. Folhas 3-5-nérveas na base ou ligeiramente acima desta, pecioladas, glabras a pilosas ou hirsutas, tricomas simples. Inflorescências terminais ou axilares, variadas. Flores 4-5-meras, até $3 \mathrm{~cm}$ compr. (normalmente menores); sépalas livres, imbricadas; corola valvar, creme ou alva, carnosa, geralmente pilosa a serícea; tubo cilíndrico, internamente piloso, lobos sub-eretos a patentes na antese. Bagas carnosas, coriáceas ou lenhosas, indeiscentes, ovóides a globosas, 1-10 cm diâm.; sementes ovóides a discóidais, 1-2muitas por lóculo.

O gênero consiste de cerca de 190 espécies pantropicais. No neotrópico, tem como centro de diversidade a Bacia Amazônica. Trata-se de um gênero extremamente bem representado na Reserva Ducke.

\section{Chave para identificação das espécies de Strychnos}

1. Inflorescências axilares ou, se terminais, desprovidas de pedúnculo.

2. Inflorescências ramificadas, paniculadas.

3. Folhas pálidas quando secas, glaucescentes em ambas as superficies; racemos quase tão longos como as folhas; flores diminutas, ca. $3 \mathrm{~mm}$ compr.; frutos enegrecidos quando secos 10. S. parviflora

3. Folhas amareladas ou verde-amareladas quando secas, não glaucas; racemos não ultrapassando a metade inferior das folhas; flores com mais de $10 \mathrm{~mm}$ compr.; frutos castanhos quando secos, opacos 11. S. peckii

2. Inflorescências congestas, densas, pouco ramificadas.

4. Inflorescências subterminais e axilares; frutos lenticelados, lenhosos, atingindo $6 \mathrm{~cm}$ diâm., às vezes pareados no final dos ramos

4. Inflorescências todas axilares; frutos não lenticelados, coriáceos ou membranáceos, até $5 \mathrm{~cm}$ diâm., mas geralmente menores. 
5. Folhas completamente cobertas de tricomas eretos, ferrugíneos; lâmina foliar amarelada quando seca.

5. Folhas com tricomas adpressos na face inferior, próximo à base, até glabras; lâmina foliar verde-acinzentada a castanho-avermelhada quando seca.

6. Pequenos arbustos ou trepadeiras, base das folhas subcordada a cordada

12. S. subcordata

6. Arbustos a lianas de grande porte; base das folhas arredondada a cuneada.

7. Folhas cinza-esverdeadas quando secas, opacas, aréolas com tubérculos microscópicos na superfície superior das folhas.

8. Retículo saliente; brácteas desenvolvidas, ocultando os ramos da inflorescência.

8. Retículo indistinto; brácteas diminutas, não ocultando os ramos da inflorescência 9. S. melinoniana

7. Folhas amareladas, amarelo-esverdeadas, castanhas ou castanho-avermelhadas quando secas, aréolas sem tubérculos microscópicos na superfície superior das folhas.

9. Folhas secas com a face superior amarela a amarelo-esverdeada, face inferior cinérea; fruto coriáceo, permanecendo globoso e tornando-se rugoso ao secar

7. S. krukoffiana

9. Folhas secas castanhas a castanho-avermelhadas; fruto coriáceo a membranáceo, brilhante, geralmente secando de maneira semelhante a uma ameixa-seca. 10. Folhas e ramos glabros; lâmina foliar oval-lanceolada a orbicular ........ 4. S. glabra

10. Ramos pilosos, folhas levemente pilosas a glabrescentes; lâmina foliar oboval.....

5. S. guianensis

1. Inflorescências terminais, pedunculadas.

11. Folhas amareladas quando secas, coriáceas; frutos até $3 \mathrm{~cm}$ diâm.

8. S. macrophylla

11. Folhas enegrecidas ou verde-acinzentadas quando secas; frutos maiores, geralmente com mais de $5 \mathrm{~cm}$ diâm. 1. S. asperula

4.1 Strychnos asperula Sprague \& Sandw., Kew Bull. 1927: 131. 1927.

Liana de grande porte, tronco lenticelado, interiormente laranja-intenso, alburno alvo, ramos enegrecidos a verde-oliváceo escuro, glabros, mais pálidos quando velhos. Pecíolos ca. $7 \mathrm{~mm}$ compr., glabros, de cor semelhante à lâmina foliar. Lâmina foliar orbicular a oboval, 4-7,5 × 2,5-4 cm, membranácea, verde-acinzentado escura até enegrecida (especialmente nas folhas jovens), brilhante, glabra, base atenuada a arredondada, ápice acuminado, 3-nérveas, veias divergentes a ca. $5 \mathrm{~mm}$ acima da base, nervuras secundárias planas na face superior, retículo indistinto, aréolas desprovidas de pontos microscópicos. Inflorescências terminais, corimbosas, pedúnculos ca. $5 \mathrm{~mm}$ compr., multifloros, com tricomas adpressos, ferrugíneos e pequenas brácteas. Flores 4-meras, até $6 \mathrm{~mm}$ compr.; cálice ca. $0,8 \mathrm{~mm}$ compr., não ultrapassando o comprimento do tubo da corola; tubo da corola $5 \mathrm{~mm}$ compr., pubérulo a papiloso, lobos até $1,5 \mathrm{~mm}$ compr., triangulares, internamente barbados na base. Frutos solitários, globosos, muito duros, $5 \mathrm{~cm}$ diâm. ou mais, brilhantes, rugosos, exocarpo destacando-se do mesocarpo; muitas sementes discóides a subglobosas por fruto.

Amazônia brasileira.

Floresta de terra firme; solo argiloso. 
Vicentini 707 (K)

Espécimes adicionais estudados: BRASIL. ACRE: Seringal S. Francisco, IX.1911, Ule 4838 (K, isótipo); Sena Madureira, 17.9.1968, Prance et al. 7593 (INPA); AMAZONAS: Rodovia ManausItacoatiara, km 29, Res. CEPLAC, 24.12.1974, fr., Prance \& Ramos 23153 (K, INPA).

Pertencente à Secção Longiflorae, este táxon diferencia-se facilmente dos outros devido às suas inflorescências corimbosas, terminais, curtamente pedunculadas e através de seus frutos grandes, solitários. Pontos microscópicos espalhados em ambas as superfícies das folhas foram observados no material-tipo de $S$. asperula, no entanto o material proveniente da Reserva Ducke não apresenta esse caráter.

4.2 Strychnos cogens Bentham, J. Bot. 3: 241.1841.

Fig. 1 a

Liana de grande porte, tronco castanhoacinzentado, internamente creme e alburno crème, ramos acinzentados, os mais velhos com lenticelas arredondadas. Pecíolos até $7 \mathrm{~mm}$ compr., densamente pilosos, não muito mais escuros do que a lâmina foliar. Lâmina foliar oval a lanceolada, $8-12(-15) \times 4-7 \mathrm{~cm}$, cartácea, cinza-esverdeado quando seca, opaca, levemente pilosa a glabra, base arredondada a cuneada, ápice agudo a acuminado, 3-nérvea, veias divergentes a ca. $7 \mathrm{~mm}$ acima da base, nervuras secundárias impressas na face superior, retículo saliente, aréolas microscopicamente tuberculadas. Inflorescências axilares, em cimeiras sésseis, densas, 8-10-floras, ferrugíneas, brácteas encobrindo os ramos da inflorescência. Flores 5-meras, até $5 \mathrm{~mm}$ compr.; cálice ca. $2 \mathrm{~mm}$ compr., não ultrapassando o comprimento do tubo da corola; tubo da corola $2,5 \mathrm{~mm}$ compr., externamente glabro; lobos até $3 \mathrm{~mm}$ compr., triangulares, internamente barbados. Frutos solitários, arredondados, amassados e com aparência de ameixas secas quando prensados, ca. 2 cm diâm., lisos, brilhantes, exocarpo muito fino, destacando-se do mesocarpo; 1-2 sementes discóides por fruto.

Amazônia Brasileira e Guianas.

Floresta de terra firme; solo argiloso. 30.VI.1993 (fr.) Ribeiro 946 (K); 12. III.1957 (fl.) L. Coelho s.n. (INPA 5202); 14.VIII.1957 (fr.) W. Rodrigues 537 (INPA).

Coleções duvidosas (estéreis): $90 \mathrm{~km}$ NNE de Manaus, Distrito Agropeca. Suframa, BR 174, km 64, 2²5' S, 5954' W, 8.XII.1989, P. Kukle 164 (INPA) p.p., excl. frutos (Menispermaceae).

Espécimes adicionais estudados: BRASIL. AMAZONAS: Manaus, road to Aleixo, Aug.-Sept. 1936, Krukoff 8001 (K).

Strychnos cogens pertence à Secção Intermedia e pode ser diferenciado das outras espécies através de suas folhas minutamente reticuladas e das aréolas dotadas de tubérculos microscópicos que conferem uma textura opaca característica às folhas.

4.3 Strychnos froesii Ducke, An. Acad. Bras. Ciên. 23: 209. 1951.

Liana de grande porte, tronco castanho escuro, finamente reticulado, internamente castanho-alaranjado, alburno amarelo com listras castanhas, ramos e gavinhas densamente recobertos por indumento ferrugíneo, glabrescentes quando velhos. Pecíolos até $7 \mathrm{~mm}$ compr., densamente ferrugíneos. Lâmina foliar orbicular, oboval, oval ou oblonga, 5-11 ×4-5,5 cm, cartácea, verde-amarelada quando seca, opaca, coberta em ambas as faces por tricomas ferrugíneos eretos, base arredondada até cuneada, ápice acuminado, 5(-7)-nérveas divergindo na basa ou ligeiramente acima desta, nervuras secundárias impressas na face superior, retículo indistinto, aréolas desprovidas de pontos ou tubérculos microscópicos. Inflorescências axilares, em cimeiras densas, sésseis, 9-16floras, densamente ferrugíneas, brácteas encobrindo os ramos da inflorescência. Flores 4-meras, até $8 \mathrm{~mm}$ compr.; cálice ca. $2 \mathrm{~mm}$ compr., não ultrapassando o comprimento do tubo da corola; tubo da corola $7 \mathrm{~mm}$ compr., densamente ferrugíneo; lobos até $2 \mathrm{~mm}$ compr., curtamente triangulares, internamente barbados 
apenas na base. Frutos 1(-2) por nó, arredondados, rígidos, coriáceos a lenhosos, não sofrendo modificações quando prensados, $2 \mathrm{~cm}$ diâm., negros, brilhantes, rugulosos, exocarpo indistinto do mesocarpo, ca. $2 \mathrm{~mm}$ de espessura; 1-3 sementes discóides por fruto.

Amazônia brasileira.

Floresta de terra firme; solo argiloso e arenoso.

5.XI.1994 (fl.) Sothers 258 (INPA K NY); 10.II.1995

(fr) Sothers 313 (INPA K); III.1957 (fr.) Coelho s.n. (INPA 1154); Estrada de Tarumã, 10.V.1953, Fróes 29613 (INPA).

Coleções duvidosas (estéreis): Rodovia Itacoatiara, km 134, 7.IX.1974, Monteiro P23126 (INPA) determinado como $S$. hirsuta Spruce por Krukoff 1979, sendo que Ducke (1955) menciona que espécimes estéreis de $S$. froesii são frequentemente confundidos com S. hirsuta.

Strychnos froesii pretence à Secção Longiflorae e difere de outras espécies do gênero por apresentar indumento ferrugíneo denso, composto por tricomas curtos nos ramos, pecíolos e inflorescências, e tricomas longos, eretos, com base mais larga, em ambas as faces das folhas. As coleções citadas acima como duvidosas apresentam ramos recobertos por tricomas retos e longos.

4.4 Strychnos glabra Sagot ex Progel, in Mart. Fl. bras. 6(1): 275. 1868.

Liana, casca espessa, ritidomatosa, castanho-escura, internamente amareloalaranjada, alburno creme, ramos e gavinhas castanho-escuros a acinzentados, glabros ou pubérulos, mais pálidos e com lenticelas lineares quando velhos. Pecíolos até $8 \mathrm{~mm}$ compr., levemente híspidos, pouco mais escuros que a lâmina foliar. Lâmina foliar oval a orbicular, 4-8 ×3-4 cm, firmemente cartácea, castanhoacinzentada ou castanho-escura quando seca, brilhante, glabrescente, base arredondada, ápice acuminado a apiculado, 3-nérveas na base, peninérveas distalmente, nervuras secundárias salientes na face superior, retículo visível, aréolas com pontos microscópicos. Inflorescências axilares em cimeiras densas, sésseis, 6-8-floras, glabrescentes, brácteas pequenas. Flores 5-meras, até $5 \mathrm{~mm}$ compr.; cálice ca. $2 \mathrm{~mm}$ compr., não ultrapassando o comprimento do tubo da corola; tubo da corola 2,5 mm compr., glabro; lobos até $3 \mathrm{~mm}$ compr., estreitamente triangulares, internamente profusamente barbados. Frutos 1-2 por nó, arredondados a obovóides, subcoriáceos a membranáceos, quando secos às vezes amassados relembrando ameixas secas, 11,5 cm diam., lisos, castanho-escuros a enegrecidos, exocarpo fino; uma semente ovóide por fruto.

Amazônia brasileira e Guianas.

Em beira de rios e em mata de várzea; solo arenoso ou argiloso.

25.V.1995 (fl.) Ribeiro 1634 (INPA, K, NY); 13.XI.1957, E. Ferreira 173 (INPA); Manaus, margem do Igarapé da Cachoeira Grande do Tarumã, 27.XII. 1954, W. Rodrigues 449 (INPA).

Estéril (S. cf. glabra): Res. Ducke, 28.VII.1976, Oliveira s.n. (INPA 59620).

Espécimes adicionais estudados: BRASIL. AMAZONAS: Manaus, Col. João Alfredo, 5.I.1942, Krukoff 859 (K); 1.III.1946, Ducke 1925 (K).

Strychnos glabra pertence à Secção Intermedia e é próxima de $S$. guianensis e S. subcordata, das quais pode ser diferenciada através de sua venação, que tende ao padrão peninérveo. Na Reserva Ducke esta espécie é frequentemente associada a uma galha foliar em formato de drusa, o que auxilia na sua pronta identificação, mesmo em estado vegetativo.

4.5 Strychnos guianensis (Aubl.) Mart., Syst. Mat. Med. Bras., 121. $1843 . \quad$ Fig. 1 d

Trepadeiras pequenas a médias, atingindo $10 \mathrm{~m}$ tall, ramos curtamente velutinos, pubérulos passando a glabrescentes, lisos e cinza-claros a acastanhados quando velhos. Pecíolos até $7 \mathrm{~mm}$ compr., usualmente mais curtos, pubescentes. Lâmina foliar oval a oboval, 2,5-6,5 × 1,5-3 cm, cartácea (talvez levemente suculenta quando fresca), castanhoavermelhado escura a castanho-acinzentada quando seca, discolorr, opaca, com alguns tricomas alvos, adpressos, passando a 
glabrescente, base cuneada, ápice acuminado a obtuso, 3-nérveas na base, nervuras secundárias ligeiramente salientes na face superior, retículo indistinto, aréolas desprovidas de pontos ou tubérculos microscópicos. Inflorescências axilares, em cimeiras 6-floras subsésseis, dotadas de tricomas adpressos avermelhados e pequenas brácteas. Flores 5-meras, até 4 mm compr.; cálice 1,5 mm, não ultrapassando o comprimento do tubo da corola; tubo da corola $2 \mathrm{~mm}$ compr., glabro; lobos até $2 \mathrm{~mm}$ compr., triangulares, internamente dotados de tricomas longos. Frutos em pequenos grupos de 1-4 por nó, globosos, subcoriáceos a membranáceos, amassados quando secos, assemelhando-se a ameixas secas, 1-1,5 cm diam., lisos, enegrecidos, exocarpo fino; $1(-2)$ sementes mais ou menos discóides por fruto.

Amazônia brasileira e Guianas.

Em floresta de várzea e de terra firme; solo arenoso ou argiloso.

Manaus, Rio Tarumã, 8.III.1946, Ducke 1926 (K); Cachoeira Baixa Tarumã, 24.III.1971, Prance et al. $11617(\mathrm{~K})$

Espécimes adicionais estudados: BRASIL. AMAZONAS: Distrito Agropecuário, Res. 1501, 2024'S 59043'W, 5.XII.1988, Boom et al. 8740 (K); ibidem, BR 174, km 72, 2019'S, 605'W, 13.II.1992, Nee 42550 (INPA); Manaus-Itacoatiara Hwy, Rio Urubu, nr. Ferry, 3.IV.1967, Prance et al. 4728 (K); Rio Preto, 29.V.1964, W. Rodrigues \& Coelho 5846 (INPA); along Cuiuini River, 0046'S, 62013'W, 13.VIII.1996, Acevedo Rdgz. et al. 8248 (INPA).

S. guianensis pertence à Secção Intermedia, sendo representada por uma série de populações polimórficas, tendo outrora englobado táxons hoje em dia (Krukoff \& Barneby 1969) reconhecidos como espécies, como por exemplo $S$. glabra e $S$. subcordata. Na região de Manaus S. guianensis apresenta folhas pequenas, obovais, através das quais efetuamos a sua distinção.

4.6 Strychnos jobertiana Baillon, Adansonia 12: 367.1879.

Fig. 1 f

Liana até $18 \mathrm{~m}$ alt., tronco creme, levemente acastanhado ou acinzentado, internamente castanho-claro a esverdeado, alburno creme, levemente listrado, ramos castanho-avermelhados, tornando-se cinzaclaros na maturidade. Pecíolos até $1 \mathrm{~cm}$ compr., às vezes pilosos, levemente mais escuros do que a lâmina foliar. Lâmina foliar oval-lanceolada a oblonga, 8-17 ×3,5-7 cm, firmemente cartácea, olivácea até verdeacinzentado quando seca, moderada-mente brilhante, glabra, base arredondada a cuneada, ápice acuminado, 3-nérvea na base, nervuras secundárias salientes na face superior, retículo visível, aréolas desprovidas de pontos ou tubérculos microscópicos. Inflorescências axilares a subterminais, sésseis, densas, multifloras, hispídulas, brácteas pequenas. Flores 4-meras, 8-9 mm compr.; cálice $1 \mathrm{~mm}$ compr., não ultrapassando o comprimento do tubo da corola; tubo da corola 6-7 $\mathrm{mm}$ compr., glabro; lobos até $2 \mathrm{~mm}$ compr., triangulares, internamente dotados de pequena quantidade de tricomas. Frutos solitários ou, mais frequentemente, em pares, globosos, lenhosos, 4-5(-7) cm diam., ásperos, com lenticelas alvas, exocarpo e mesocarpo indistinguíveis, mais de $5 \mathrm{~mm}$ de espessura; muitas sementes mais ou menos discóides por fruto.

Amazônia brasileira.

Geralmente em floresta de terra firme; solo argiloso.

16.II.1995 (fr) Hopkins 1556 (INPA NY); 16.XII.1996

(fl) Sothers 966 (INPA K); 3.VI.1993 (fr) Ribeiro 825 (INPA, K, NY); 3.X.1957 (fr) E. Ferreira 135 (INPA).

Espécimes adicionais estudados: BRASIL. AMAZONAS: Rodovia Manaus-Itacoatiara, km 31, CEPLAC, XI.1973, Steward \& Ramos P 17673 (K); km 133, 15.VII.1974, fr., W. Rodgrigues \& Loureiro 9519 (INPA); Manaus-Caracaraí Road, km 148, 26.IX.1973, fl, Bisby et al. P 18127 (INPA); Vaupés, Rio Negro, Jauareté, 19.X.1945, fl, Froes 21215 (K).

Espécime estéril ( $S$. cf. jobertiana): CEPLAC, Manaus Itacoatiara Rd, km 29, 19.IX.1974, Prance \& Ehrendorfer 22730 (INPA).

Strychnos jobertiana pretence à Secção Longiflorae e pode ser facilmente distinguido das outras espécies através de seus 
frutos, geralmente pareados e extremamente lenhosos, alvos a acinzentados. A nervação secundária saliente na face superior também é útil na sua identificação, sendo a única espécie do gênero na Reserva Ducke a apresentar essa característica.

4.7 Strychnos krukoffiana Ducke, Trop. Woods 90: 27. 1947.

Liana até $8 \mathrm{~m}$ alt., caule e ramos fissurados. Pecíolos até $1 \mathrm{~cm}$ compr., híspidos, mais escuros do que a lâmina foliar. Lâmina foliar oblonga a largamente elíptica, 6-12 $\times$ 3,5-5 cm, coriácea, amarelo-esverdeada e brilhante na face superior quando seca, cinérea e glaucescente na face inferior, glabra ou com tricomas eretos muito curtos na face inferior, base arredondada, ápice curtamente acuminado, 5(-7)-nérvea divergindo ca. $5 \mathrm{~mm}$ acima da base, nervuras secundárias marcadamente impressas na face sperior, retículo indistinto, aréolas desprovidas de pontos ou tubérculos microscópicos. Inflorescências axilares, cimosas, sésseis, multifloras, híspidas, bracteadas. Flores (não observadas, dados da literature) 4-meras, até $6 \mathrm{~mm}$ compr.; cálice ca. $0,8 \mathrm{~mm}$ compr., não ultrapassando o comprimento do tubo da corola, tubo da corola $4 \mathrm{~mm}$ compr., lobos até $2 \mathrm{~mm}$ compr. Frutos 1-2(-3) por nó, depresso-globosos, lenhosos, ca. 2,5 cm diâm., quebradiços, minutamente rugosos e brilhantes, enegrecidos, exocarpo e mesocarpo indistitnos, ca. 1,5 mm espessura; 4 sementes discóides por fruto.

Endêmica de Manaus.

Floresta de terra firme. Reserva 1501, km 41, 2 ${ }^{\circ} 24^{\prime}-2^{\circ} 25^{\prime} \mathrm{S}, 59^{\circ} 43^{\prime}-59^{\circ} 45^{\prime} \mathrm{W}$, 50-125 m, 7.XII.1988, B. Boomet al. 8778 (INPA, K).

Strychnos krukoffiana pertence à Secção Longiflorae, tendo permanecido pouco conhecida após a perda da única planta conhecida durante os anos cinquienta, antes que Ducke pudesse descrever os seus frutos (Ducke 1955). A descrição completa dos mesmos é aqui apresentada pela primeira vez, sendo que algumas características dos mesmos (dureza, brilho, microestrutura) são úteis para diferenciar S. krukoffiana de outras espécies ocorrentes na Reserva Ducke.

4.8 Strychnos macrophylla Barb. Rodr., Vellosia, ed. 2, 1:33.1891. Fig. 1 c, e

Liana de grande porte, tronco acinzentado, longitudinalmente fissurado, ramos adpressopilosos quando jovens. Pecíolos até $10 \mathrm{~mm}$ compr., pilosos, mais escuros do que a lâmina foliar. Lâmina foliar amplamente oval a arredondada, 6-20 × 4-9 cm, coriácea quando atinge a maturidade, amarelo-ocráceo até castanho-clara quando seca, brilhante na face superior, pilosa ao longo das nervuras quando jovem, base arredondaada a cuneada, ápice abruptamente acuminado, 3(-5)-nérvea, às vezes divergindo $10 \mathrm{~mm}$ acima da base e alternadamente, nervuras secundárias levemente salientes até canaliculadas na face superior, retículo indistinto a visível, aréolas desprovidas de pontos ou tubérculos microscópicos. Inflorescência terminal, pedunculada, subcorimbosa, multiflora, tricomas adpressos, ferrugíneos, brácteas inconspícuas. Flores 5-meras, até $12 \mathrm{~mm}$ compr.; cálice 1,52 mm compr., não ultrapassando o comprimento do tubo da corola; tubo da corola $8 \mathrm{~mm}$ compr., curtamente piloso até papiloso; lobos até $2,5 \mathrm{~mm}$ compr., ovais, internamente pilosos na base. Frutos ovóides a arredondados, apiculados, lenhosos, até $3 \mathrm{~cm}$ diam., opacos, alvosa castanho-claros, lenticelados, exocarpo e mesocarpo indistinguíveis, até $1,5 \mathrm{~mm}$ espessura; 2 sementes oblongas até discóides por fruto.

Conhecida apenas da região de Manaus. CEPLAC, km 29 Rodovia Manaus-Itacoatiara, 19.IX.1974, Prance \& Ehrendorfer 22731 (INPA, K); Manaus, Cachoeirinha, 14.IX.1929, Ducke s.n. (RB 22361, INPA); estrada do Crespo, 4.III.1945, Lemos Fróes 20566 (K); BR 17, km 3, 21.XII.1955, Coelho \& Mello s.n. (INPA 3163); estrada do Aleixo, III.1945, Lemos Fróes 20488 (K); Mauá Road, 23.III.1971, Prance et al. 11539 (K).

Strychnos macrophylla pertence à Secção Longiflorae, sendo suas características diagnósticas a inflorescência apical, as folhas 
coriáceas amareladas quando secas e os seus frutos rígidos, opacos e apiculados. Trata-se de uma das espécies integrantes de um complexo envolvendo a amplamente distribuída $S$. rondetelioides Spruce e S. barnhardtiana Krukoff, conhecida apenas do alto Rio Solimões, nas proximidades de São Paulo de Olivença, e a diferenciação entre essas espécies baseia-se em caracteres presentes nos frutos. Infelizmente material frutífero desses três táxons é extremamente escasso para permitir um julgamento mais apurado a respeito do reconhecimento e/ou sinonimização desses táxons.

4.9 Strychnos melinoniana Baill., Bull. Soca. Linn. Paris 1: 256. 1880.

Liana de grande porte, até $20 \mathrm{~m}$ alt., ramos e gavinhas acinzentadas, com lenticelas verticais na maturidade. Pecíolos até $1 \mathrm{~cm}$ compr., glabros, mais escuros que a lâmina foliar. Lâmina foliar oval a lanceolada, elíptica ou oblonga, 8-16 × 3,5-7 cm, coriácea, ocre até castanho-clara quando seca, brilhante na face superior, sub-glauca inferiormente, base arredondada a atenuada, ápice agudo, 3-5nérvea, par superior de nervuras divergindo aproximadamente $1 \mathrm{~cm}$ acima da base, nervuras secundárias salientes a canaliculadas na face inferior, retículo visível, aréolas com pontos microscópicos. Inflorescências axilares, subsésseis, multifloras, densas, pubérulas a densamente curto-ferrugíneas, brácteas não ocultando a ramificação. Flores 5-meras, 6-7 mm compr.; cálice $1 \mathrm{~mm}$ compr., não ultrapassando o comprimento do tubo da corola; tubo da corola $3 \mathrm{~mm}$ compr., glabro; lobos até 3 $\mathrm{mm}$ compr., estreitamente triangulares, completamente cobertos internamente por tricomas longos, alvos. Frutos em cachos densos de ambos os lados do ramo, estreitamente obovóides, amassados quando secos, com aparência de ameixas secas, até 2 cm diâm., rugosos, negros, exocarpo delgado, indistinto do mesocarpo; $1-2$ sementes discóides por fruto.

Amazônia brasileira e Guianas.
Floresta de terra firme.

Estrada Manaus-Caracaraí, km 57, 15.IX.1977, CA. D. A. Mota 673 (INPA)

Coleções duvidosas (estéreis): Reserva Ducke, 11.IV.1967, Prance et al. 4794, 4801 (INPA).

Espécimes adicionais estudados: BRASIL. AMAZONAS: Borba, BR 230, $3 \mathrm{~km}$ E Sucunduri, 6050'S, 5900'W, 6.V.1985, A. Henderson et al. 305 (K); PARÁ: Rodovia Belém-Brasília km 93, 29.VIII.1959, Kuhlmann \& Jimbo 163 (K). British Guiana, Essequibo River, Moraballi Creek, 26.IX.1929, Sandwith 342 (K).

Strychnos melinoniana pertence à Secção Longiflorae, e pode ser facilmente distinguido através dos seus frutos ovóides, de exocarpo delgado, pendendo em cachos densos na maturidade.

4.10 Strychnos parviflora Spruce ex Benth., Jour. Linn. Soc. 1: 107. $1856 . \quad$ Fig. 1 b

Liana de grande porte, atingindo $40 \mathrm{~m}$ alt., tronco liso, ramos acinzentados, adpressamente pubérulos a glabrescentes. Pecíolo até $12 \mathrm{~mm}$ compr., pubérulo, mais escuro que a lâmina foliar. Lâmina foliar oboval a largamente-elíptica, $8-17 \times 3,5-7,5 \mathrm{~cm}$, coriácea, creme-amarelado clara quando seca e brilhante na face superior, glauca e cremepálida na face inferior, glabra, base arredondada, ápice abruptamente acuminado, 3(-5)-nérvea, nervuras secundárias impressas a planas na face superior, retículo indistinto, aréolas com tubérculos microscópicos na face superior. Inflorescências axilares, paniculadas, bem desenvolvidas, quase tão longas quanto as folhas, pedunculadas, multifloras, densamente curtamente velutinas, brácteas arredondadas. Flores 5-meras, até $3 \mathrm{~mm}$ compr., cálice ca. $0,7 \mathrm{~mm}$ compr., ultrapassando o comprimento do tubo da corola, tubo da corola $0,5 \mathrm{~mm}$ compr., seríceos; lobos da corola oblongos, internamente alvo-barbados. Fruto elipsóide, às vezes apiculado, rígido, até $4 \mathrm{~cm}$ diam., exocarpo mole, carnoso, enrugado, mesocarpo lignificado, castanho-escuro até enegrecidos (freqüentemente com uma tonalidade glauca), opaco; até 4 sementes discóides por fruto.

Cipó-cravo 
Amazônia brasileira e Peru.

Floresta de terra firme e de várzea, próximo de cursos d'água.

Manaus, Igarapé do Passarinho, 18.X.1957, E. Ferreira 149/57 (INPA); Igarapé do Mariano, BR 17, km 30, 4.II.1957, J. Chagas s.n. (INPA 5572); 1.cit., 4.VII.1957, L. Coelho s.n. (INPA 5571).

Espécimes adicionais estudados: AMAZONAS: Rio Uaupés, IX.1852, Spruce 2482 (K, holótipo); Vaupés, Jauareté, 23.X.1945, Lemos Fróes 21269 (K); Rio Negro, Serra Cabary, 500 m alt., 2.XII.1945, L. Fróes 21461 (K); Esperança (mouth of Javary), 23.IX.1942, Ducke 1110 (K); São Paulo de Olivença, 26.X.1936-11.XII.1936, Krukoff 9079, 9087, 9104, $9115(\mathrm{~K})$.

Strychnos parviflora pertence à Secção Breviflorae, e a combinação incomum de inflorescências axilares muito ramificadas e folhas creme-amareladas diferencia esta espécie das outras. De acordo com Ducke (1955), S. parviflora pode ser reconhecido facilmente, mesmo em estado estéril, devido ao seu odor característico de cravo-da-índia, refletido por seu nome vernacular. Os frutos são chamados de "pitomba" e consumidos por crianças na Amazônia (Ducke 1955).

4.11 Strychnos peckii B.L. Robinson, Proc. Am. Acad. 49: 504. 1913.

Trepadeira de grande porte atingindo 30 $\mathrm{m}$ alt., tronco fissurado, castanho-acinzentado, ramos castanho-escuros, por vezes curtamente pilosos. Pecíolos até $14 \mathrm{~mm}$ compr., curtamente pilosos quando jovens, secando mais escuros do que a lâmina foliar. Lâmina foliar elíptica a oblonga, $10-20(-24) \times 3,5-8$ $(-15) \mathrm{cm}$, coriácea a subcoriácea, secando amarela a verde-olivácea, fosca, concolora, glabra (ou pubescente ao longo das nervuras quando jovem), base arredondada a cuneada, ápice acuminado, 5-nérvea, par superior de nervuras divergindo ca. $1 \mathrm{~cm}$ acima da base, nervuras secundárias planas a levemente impressas na face superior, retículo visível, aréolas com pontos microscópicos na face superior, sobretudo acompanhando as nervuras. Inflorescências axilares, sésseis, paniculadas, não ultrapassando metade do comprimento das folhas, multifloras, curtamente adpresso-pilosas, ferrugíneas, brácteas inconspícuas. Flores 5-meras, até $12 \mathrm{~mm}$ compr.; cálice 0,5-0,7 mm compr.; tubo da corola $8 \mathrm{~mm}$ compr., mais largo na base, curtamente adpresso-piloso; lobos até $2,5 \mathrm{~mm}$ compr., ovados a triangulares, barbados internamente. Frutos 1(-3) por nó, globosos, lignificados, até $7 \mathrm{~cm}$ diâm., foscos, lenticelados, castanho-amarelado claros, exocarpo e mesocarpo indistintos, até $3 \mathrm{~mm}$ de espessura; numerosas sementes discóides por fruto.

Desde Belize até as Guianas e Amazônia brasileira, alcançando o estado do Mato Grosso.

Floresta de terra firme e de igapó. Manaus, Igarapé do Passarinho, 22.X.1956, L. Coelho \& Chagas s.n. (INPA 4289); Igarapé do Mariano, Br 17, km 30, 4.VII.1957, L. Coelho s.n. (INPA 5570); Reserva Florestal Ducke, 11.IV.1967, Prance et al. 4802 (INPA)

Coleções duvidosas (estéreis): Reserva Ducke, 11.IV.1967, Prance et al. 4794, 4801, 4803 (INPA); 1.XI.1972, W. Rodrigues 9182 (INPA).

Espécimes adicionais estudados: BRASIL. PARÁ: Bragança, 13.X.1923, Ducke s.n. (INPA 18538, K); Belém, 17.XI.1922, Ducke s.n. (INPA 18536, K); AMAZONAS: Barcelos, 13.VI.1905, Ducke 7175 (INPA 22360, K); São Paulo de Olivença, II.1936, Krukoff 7627, 7629, 7631 (K); loc.cit., I.1936, Krukoff 7581 (K).

Strychnos peckii pertence à Secção Longiflorae, e pode ser diferenciada das outras espécies através de suas folhas de grandes dimensões (especialmente em espécimes estéreis), lâmina normalmente secando amarelada, e frutos lignificados, fortemente lenticelados, que relembram os frutos de S. jobertiana. S. peckii parece próximo de S. erichsonii M.R. Schomb., sendo freqüentemente erroneamente identificado como esta espécie, no entanto $S$. erichsonii possui frutos macios e menores.

4.12 Strychnos subcordata Spruce ex Benth., Journ. Linn. Soca. 1: 106. 1856. 
Arbusto ereto de 1,5 m alt. ou trepadeira de pequeno porte, tronco acinzentado, ramos castanho-escuros, pilosos. Pecíolos até $2 \mathrm{~mm}$ compr., alvo-pilosos. Lâmina foliar oval a arredondada, (1-)2-7 × (0,5)1,2-2,5(-3,5) cm, membranácea, secando verde-acinzentada a castanho-escura, fosca até brilhante na face superior, alvo-pilosa especialmente nas nervuras e na face inferior, base subcordada a cordada, ápice agudo, 3-nérvea, nervuras às vezes divergindo $5 \mathrm{~mm}$ acima da base, nervuras secundárias levemente salientes na face superior, retículo indistinto até visível, aréolas desprovidas de pontos ou tubérculos microscópicos. Inflorescências axilares, sésseis, 3-6-floras, densamente híspidoferrugíneas, brácteas inconspícuas. Flores 4-meras, até $4 \mathrm{~mm}$ compr.; cálice ca. $1 \mathrm{~mm}$ compr., ultrapassando o comprimento do tubo da corola; tubo da corola $8 \mathrm{~mm}$ compr., glabro; lobos até $3 \mathrm{~mm}$ compr., ovais, base dos lobos barbada. Frutos globosos, secando de modo semelhante a ameixas-secas, até $2 \mathrm{~cm}$ diam., castanho-escuros e moderadamente brilhantes, exocarpo fino, minutamente tuberculado; $1(-2)$ sementes discóides por fruto.

Murta-da-mata.

Amazônia brasileira.

Floresta de terra firme e mata secundária, solo argiloso.

Reserva Ducke, 27.V.1976, Aluísio s.n. (INPA 71739); 1..cit., 11.IV.1967, Prance et al. 4793 (INPA). Espécimes adicionais estudados: BRASIL. AMAZONAS: São Paulo de Olivença, VII.1936, Krukoff 7807 (K); Manaus, estrada do Aleixo, Campus do INPA, 30.III.1984, Cid et al. 4291 (INPA); 1.cit.., 12.XII.1974, Gentry 13222 (INPA); Aleixo, road to Porto Mauá, 23.IV.1970, W. Rodrigues 8858 (INPA); Igarapé do Franco, 17.X.1958, D. Coelho 12 (INPA); Mauá Road, 24.III.1971, Prance et al. 11578 (INPA).

Strychnos subcordata pertence à Secção Intermedia, sendo relacionado com $S$. glabra e S. guianensis, das quais difere através do seu porte, indumento e de suas folhas subcordadas de dimensões diminutas.

Espécies pouco conhecidas, mas provavelmente presentes na área de estudo (espécimes estéreis).

Strychnos cf. amazonica Krukoff - Reserva Ducke, 11.IV.1967 (fr) Prance 4799, 4797 (INPA).

As coleções acima apresentam folhas fortemente acuminadas, secando enegrecidas, com nervuras terciárias paralelas e conspícuas, e foram identificadas por Krukoff como $S$. amazonica, cujo tipo é proveniente do Peru (Schunke 131, NY, US, A, K!). Apesar da coloração enegrecida tais espécimes coletados na Reserva Ducke apresentam certa semelhança com S. peckii.

Strychnos cf. toxifera Schomb. ex Benth. Manaus-Caracaraí Rd, km 50, 25.VII.1975, Prance et al. 23569 (INPA, NY).

Este espécime parece-se ligeiramente com S. froesii, no entanto seus ramos apresentam tricomas eretos, híspidos, e o indumento em suas folhas é longo e uniforme, especialmente na face adaxial. Krukoff determinou o espécime como $S$. toxifera, embora esta espécie não tenha sido observada na Reserva Ducke até o presente momento. 